\title{
The use of bio-carriers and zeolite in a lab-scale MBR for membrane fouling mitigation
}

\author{
Gkotsis P.K. and Zouboulis A.I.* \\ Laboratory of Chemical and Environmental Technology, Section of Chemical Technology and Industrial Chemistry, School of Chemistry, \\ Aristotle University of Thessaloniki, 54124 Thessaloniki, Greece \\ Received: 11/12/2017, Accepted: 07/05/2018, Available online: 26/09/2018 \\ *to whom all correspondence should be addressed: e-mail: zoubouli@chem.auth.gr \\ https://doi.org/10.30955/gnj.002546
}

\begin{abstract}
The Membrane Bio-Reactor (MBR) technology offers a series of environmentally-friendly advantages, such as high quality effluent, pathogens removal capacity and avoided use of chemicals for disinfection, allowing it to be regarded as an environmentally friendly technology, when applied for wastewater treatment. However, membrane fouling still remains a major drawback, preventing its widespread application for municipal or industrial wastewater treatment. The use of additives (i.e. adsorbents, bio-carriers etc.) is considered to be among the major strategies implemented for membrane fouling control over the last few years. The present work examines the influence of bio-carriers addition, as well as of zeolite powder on the reversible and irreversible membrane fouling of a lab-scale MBR. High-strength synthetic municipal wastewater (with $\mathrm{BOD}_{5}$ around $1000 \mathrm{mg} / \mathrm{L}$ ) was fed as the substrate for the activated sludge process and a flat-sheet microfiltration membrane was operated for solids (biomass) - liquid separation at the flux of $17 \mathrm{~L} / \mathrm{m}^{2} \mathrm{~h}$. The obtained results showed that the addition of zeolite contributed mainly to the alleviation of irreversible fouling, leaving the reversible fouling practically unaffected, while the addition of bio-carriers had quite the opposite effect. In addition, it was shown that the lab-scale MBR system operated successfully, treating a high-strength synthetic municipal wastewater, as high removals were observed in terms of both organics and especially of ammonium removal (over 98\%).
\end{abstract}

Keywords: Membrane bio-reactors, reversible and irreversible fouling, membrane fouling mitigation, environmentally friendly technologies, zeolite addition, bio-carriers.

\section{Introduction}

Membrane technologies have the potential to play a significant role in preventing pollution and allowing resource recovery, chemicals' purification and energy savings. Over the last few years, a remarkable progress has been observed, regarding the application of Membrane Bio-Reactor (MBR) technology in the field of municipal and industrial wastewater treatment. In particular, Membrane Bio-Reactors can contribute to a greener chemistry by controlling better the mass transfer of reactants and products and by enhancing the overall yields and conversions, minimizing solvents' use and maximizing mass utilization. Besides, the recycling of water from municipal or industrial wastewater remains one of the most important concerns connected with the use of alternative energy sources and clean water production (Boddhoo and Harvey, 2013). Membrane Bio-Reactors (MBRs) offer a series of environmental advantages, when compared to the Conventional Activated Sludge Process (CASP), which may suggest it being viewed as an environmentally friendly technology as well, regarding mainly the reduced plant footprint, the better effluent quality, the better removal capacity of pathogens, the avoided use of supplementary chemicals for final disinfection (before discharge) and the reduced sludge production (Lofrano, 2012; Neoh et al., 2016). However, membrane fouling, which is the unwanted deposition of suspended particulates, colloids and solutes of the aeration tank mixed liquor content on the membrane surface and/or inside the membrane pores, still remains the major drawback, preventing the wider application of MBR technology (lorhemen et al., 2017). Therefore, most recent MBR studies aim to identify, investigate, control, model and mitigate the respective membrane fouling (Akamatsu et al., 2010).

The Extracellular Polymeric Substances (EPS) include a wide range of substances, such as carbohydrates, proteins, nucleic acids, lipids, humic acids etc., which are regarded as the most important foulants affecting the membrane's performance in MBRs. EPS can be classified as bound EPS (bEPS) which are located at or outside the cell surface and soluble EPS (sEPS) or SMPs (Soluble Microbial Products) which are released as a result of the substrate metabolism or biomass decay (Meng et al., 2009).

Among the various strategies employed, the use of specific additives is increasingly applied for membrane fouling mitigation (Krzeminski et al., 2017; Gkotsis et al., 
2017). Natural zeolite (clinoptilolite) is considered as one interesting material for wastewater treatment, due to its excellent ion-exchange properties, adsorption capacity and possible use as a molecule sieve (Dutta et al., 2014). As a result, numerous studies focus on the examination of its remarkable removal efficiency, regarding mainly COD, ammonium and residual colour in several wastewater treatment applications (e.g. Rezaei and Mehrnia, 2014; Wu et al., 2008; Yuniarto et al., 2013). Nevertheless, zeolite has been recently used for membrane fouling control as well. Rezaei and Mehrnia (2014) found that the addition of zeolite in a lab-scale MBR system can improve sludge properties, causing the accumulation of larger particles and reducing the Trans-Membrane Pressure (TMP). Yuniarto et al. (2013) and Damayanti et al. (2011) investigated the effect of zeolite on the operational conditions of a MBR system, treating palm oil mill effluent and showed that zeolite addition increased the membrane permeability and enhanced the critical flux. Bio-film carriers (or bio-carriers), usually made of sponge or other appropriate plastic materials, are also reported to mitigate fouling by direct physical membrane scouring and by reducing the SMP concentration (Yoon, 2016).

In most studies, fouling is principally examined in terms of membrane permeability increase or TMP reduction. To the author's best knowledge, little information has been reported regarding the influence of zeolite and bio-carriers addition, specifically on reversible or irreversible fouling in MBR systems. This study is part of a research project which investigates the effect of zeolite and bio-carriers on membrane fouling, using a lab-scale MBR system and treating high-strength synthetic municipal wastewater, with specific attention given to reversible and irreversible fouling mitigation. For this purpose, a series of batch-mode and continuous-flow experiments, which included the addition of different zeolite and bio-carriers dosages in the sludge of a lab-scale MBR, were conducted and their effect was examined on sludge filterability (used as a reversible fouling index) and on SMP concentration reduction (used as an irreversible fouling index). Although bEPS play a pivotal role in membrane fouling development and may be affected by the addition of zeolite and bio-carriers, it was decided that the SMPs will be studied as the main foulant species in the present work because they have the strongest relationship with membrane fouling rate (i.e. dTMP/dt) when compared to other sludge characteristics (i.e. MLSS, particle size distribution and bEPS) (Deng et al., 2017). After the completion of the preliminary batch-mode tests, which indicated the optimal zeolite and bio-carriers dosages, the continuous-flow experiments were launched aiming to the appropriate 'tuning' of the additives' dosages. These experiments are still being conducted and, thus, the results of the preliminary batch-mode tests are presented and discussed in this paper. It is clear that the present work, which examines the effect of additives on membrane fouling with a view to extending the membranes' operational time by minimizing their chemical cleaning, is directly related to environmentally friendly technologies and green chemistry.

\section{Materials and methods}

\subsection{Lab-scale MBR operation}

The experimental lab-scale set-up consists of four basic sub-units: (a) wastewater feed unit, (b) bioreactor, (c) membrane (side-stream) filtration, and (d) permeate collection unit (Figure 1). After the bioreactor was inoculated with activated sludge, which was received from the recirculation channel of the urban wastewater treatment plant of Thessaloniki city (located in the area of Sindos, near to Gallikos River), the system was operated continuously in order to achieve steady-state conditions in the bioreactor. The synthetic wastewater, which was fed as the substrate for the activated sludge, was led by a peristaltic pump to the aeration tank (bioreactor), where the concentration of the dissolved oxygen (DO) was monitored by a DO-meter in the range of 2-3 mg/L. The air needed for the biomass aeration (and bio-oxidation of pollutants) and for the cleaning of applied membrane was supplied by an air compressor, the pressure of which was appropriately reduced to the desired value by means of an air pressure reducer. Gas and liquid flow rates were measured by gas and liquid flow meters, while level sensors were used in order to control the liquid level in the membrane tank. The permeate was withdrawn from the upper-end of the applied membrane by another peristaltic pump, while a high-resolution pressure transmitter was placed in the outlet of the membrane in order to record the Trans-Membrane Pressure (TMP). The permeate collection unit was the final recipient of the produced permeate. Membrane relaxation steps of $1 \mathrm{~min}$ were regularly performed for mechanical cleaning purposes every $9 \mathrm{~min}$ of filtration operation. The system's performance, assessed in terms of organics $\left(\mathrm{BOD}_{5}, \mathrm{COD}\right)$ and ammonium $\left(\mathrm{NH}^{+}{ }_{4}-\mathrm{N}\right)$ removal, was deemed satisfied.

A flat sheet, microfiltration membrane (Kubota Membranes Inc., Japan) with a pore size of $0.4 \mu \mathrm{m}$ and an effective area of $0.11 \mathrm{~m}^{2}$ (made of chlorinated polyethylene) was operated at a flux of $17 \mathrm{~L} / \mathrm{m}^{2} \mathrm{~h}$. Synthetic municipal wastewater (with $\mathrm{BOD}_{5}$ around $1000 \mathrm{mg} / \mathrm{L}$ ) was fed in the activated sludge treatment system, under the following operating conditions: Sludge Retention Time $(S R T)=10 \mathrm{~d}, \mathrm{~F} / \mathrm{M}$ ratio $=0.21 \mathrm{~kg} \mathrm{BOD} / \mathrm{kg}$ MLVSS.d. In order to maintain the SRT at $10 \mathrm{~d}$, the MLSS concentration was kept constant at $7500 \mathrm{mg} / \mathrm{L}$. The COD: $\mathrm{N}$ : $\mathrm{P}$ ratio of the synthetic wastewater was 100: 14: 3 and its (typical) composition is presented in Table 1. Reversible fouling was assessed in terms of sludge filterability tests, according to the standard Time-to-Filter (TTF) method, while irreversible fouling was assessed in terms of SMP removal, after the appropriate analytical determination of SMP. The cylindrical Hel- $X$ bio-carriers of the German Christian Stöhr GmbH \& Co (type HXF12KLL, made of HDPE, $d=0.95 \mathrm{~kg} / \mathrm{L}$ ), which have been successfully used for biological wastewater treatment in many MBR applications, were added in the pilot-scale MBR. 


\subsection{Filterability tests by applying the TTF method (Time-To-Filter method)}

The Time-To-Filter (TTF) method is a well-established method, which can be used as an easy and relatively rapid way to assess sludge filterability (De la Torre et al., 2008; Rosenberger and Kraume, 2002). A 90-mm Buchner funnel is used with Whatman \#1, \#2, or equivalent filter papers. A short description of the procedure is as follows: after pouring $200 \mathrm{~mL}$ of mixed liquor on the Buchner funnel, the time required to obtain $100 \mathrm{~mL}$ of filtrate was recorded at the vacuum pressure of 510 mbar (designated as TTF100). Low TTF100 values indicate high sludge filterability, whereas high TTF100 values indicate low sludge filterability. In this study, except for the TTF100, the time required to obtain $20,40,60$ and $80 \mathrm{~mL}$ of filtrate was also recorded, in order to plot a full profile of recorded experiments, which can contribute to a better comparison and understanding of obtained results.

\subsection{SMP concentration measurements}

SMPs were extracted by the following procedure: mixed liquor samples were daily obtained from the bioreactor and centrifuged in order to separate the solid biomass. Then the Phenol-Sulfuric Acid method (DuBois et al., 1956), which is the most widely used colorimetric method for the determination of carbohydrate concentration in aqueous solutions, was applied in the supernatant for the determination of carbohydrate fraction of SMPs. The principle of this method is that carbohydrates, when dehydrated by reaction with concentrated sulfuric acid, produce furfural derivatives. Further reaction between furfural derivatives and phenol develops a detectible colour. A short description of the standard procedure is following: $1 \mathrm{~mL}$ aliquot of a carbohydrate solution was mixed with $1 \mathrm{~mL}$ of wt. $5 \%$ aqueous solution of phenol in a test tube. Subsequently, $5 \mathrm{~mL}$ of conc. $\mathrm{H}_{2} \mathrm{SO}_{4}$ were added rapidly to the mixture. After allowing the test tubes to stand for $10 \mathrm{~min}$, they were vortexed for $30 \mathrm{~s}$ and placed for $20 \mathrm{~min}$ in a water bath at room temperature for colour development. Then, light absorption at $490 \mathrm{~nm}$ was recorded on a spectrophotometer. Reference solutions were prepared in identical manner as aforementioned, except that the $1 \mathrm{~mL}$ aliquot of carbohydrate was replaced by glucose. A Hitachi UV/Vis double-beam spectrophotometer was used for these measurements.

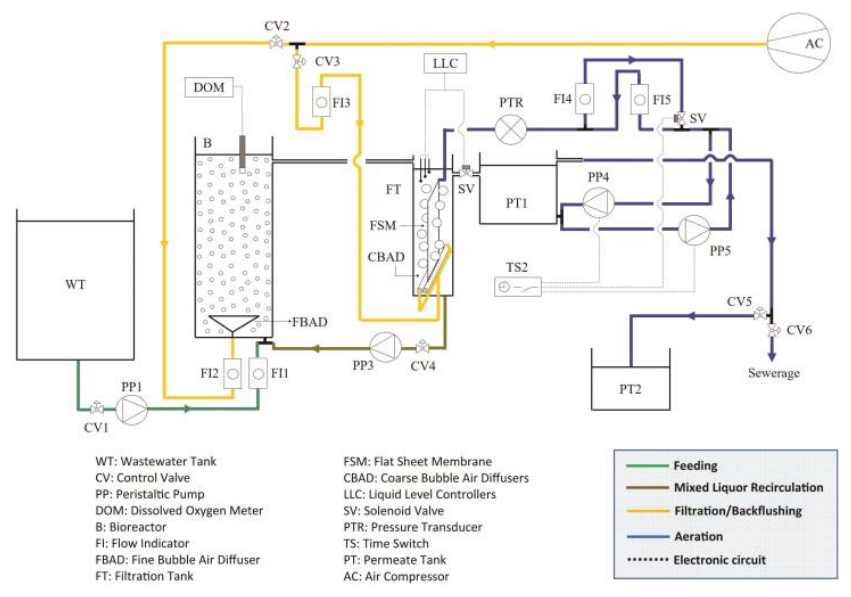

Figure 1. Schematic of the lab-scale continuous-flow MBR system

Table 1. Composition of synthetic municipal wastewater

\begin{tabular}{|c|c|c|c|}
\hline \multirow[t]{2}{*}{ Substance } & $\begin{array}{c}\text { Synthetic wastewater } \\
\text { according to OECD guidelines }\end{array}$ & $\begin{array}{c}\text { Synthetic wastewater used } \\
\text { in the experiments }\end{array}$ & \multirow{2}{*}{$\begin{array}{l}\text { Physical/chemical parameters of the synthetic } \\
\text { wastewater, which was used in the experiments } \\
\text { (average of } 30 \text { replication of measurements) }\end{array}$} \\
\hline & \multicolumn{2}{|c|}{ Concentration, $\mathrm{mg} / \mathrm{L}$} & \\
\hline Peptone & 160 & 1600 & $\mathrm{BOD}_{5} 1036 \pm 58 \mathrm{mg} / \mathrm{L}$ \\
\hline Meat extract & 110 & 1100 & COD $1987 \pm 73 \mathrm{mg} / \mathrm{L}$ \\
\hline $\mathrm{K}_{2} \mathrm{HPO}_{4}$ & 28 & 280 & $\mathrm{NH}_{4}{ }^{+}-\mathrm{N} 197 \pm 18 \mathrm{mg} / \mathrm{L}$ \\
\hline $\mathrm{NaCl}$ & 7 & 70 & $\mathrm{PO}_{4}{ }^{3}-\mathrm{P}=67 \pm 7.8 \mathrm{mg} / \mathrm{L}$ \\
\hline $\mathrm{CaCl}_{2} \cdot 2 \mathrm{H}_{2} \mathrm{O}$ & 4 & 40 & TOC $735 \mathrm{mg} / \mathrm{L}$ \\
\hline $\mathrm{MgSO}_{4} \cdot 7 \mathrm{H}_{2} \mathrm{O}$ & 2 & 20 & Turbidity 14.6 NTU \\
\hline
\end{tabular}

\section{Results and discussion}

\subsection{Fouling estimation}

For the application of zeolite, the results of batch-mode (short-term) experiments are presented in terms of the ratios $\mathrm{TTF}_{\text {additive }} / \mathrm{TTF}_{\text {no }}$ additive and $\mathrm{SMP}$ additive/SMPno additive. $\mathrm{TTF}_{\text {zeolite }} / \mathrm{TTF}_{\text {no zeolite }}$ is the ratio of $\mathrm{TTF}_{100}$ value recorded after the addition of zeolite in the mixed liquor, to the $\mathrm{TTF}_{100}$ value recorded before this addition (i.e. the respective blank measurement). It is evident that when this ratio is lower, then sludge filterability is enhanced. $\mathrm{SMP}_{\text {zeolite }} / \mathrm{SMP}_{\text {no }}$ zeolite is the ratio of SMP concentration after the addition of zeolite in the mixed liquor, to the SMP concentration before this addition (i.e. the respective blank measurement). In the same way, the lower this ratio is, the more effective the tested zeolite concentration becomes (in terms of SMP removal). The effect of zeolite on sludge filterability and SMP removal was examined at three concentrations: 1,5 and $10 \mathrm{~g} / \mathrm{L}$ (Figures 2 and 3). The horizontal line in each figure represents the blank ratio value (i.e. $\mathrm{TTF}_{\text {no }}$ zeolite/TTF no zeolite, or $\mathrm{SMP}_{\text {no zeolite }} / \mathrm{SMP}_{\text {no zeolite), which is always equal to } 1 .}$ As shown in Figure 2, the addition of zeolite at high concentration $(10 \mathrm{~g} / \mathrm{L})$ did not affect the ratio

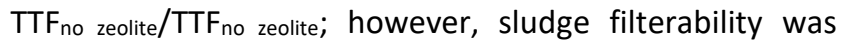
slightly improved at the lower concentrations ( 1 and $5 \mathrm{~g} / \mathrm{L}$ ). The highest SMP removal was observed at the same concentrations as well (especially at $5 \mathrm{~g} / \mathrm{L}$ ) (Figure 3). 


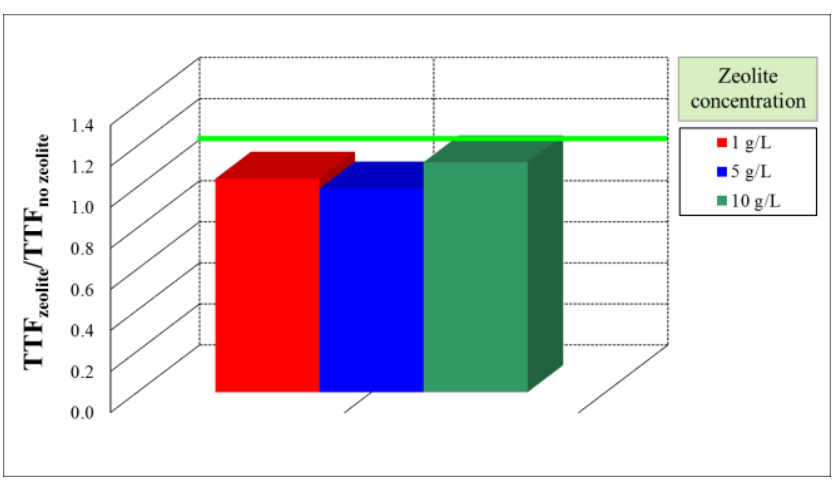

Figure 2. Effect of zeolite concentration (1, 5 and $10 \mathrm{~g} / \mathrm{L})$ on sludge filterability

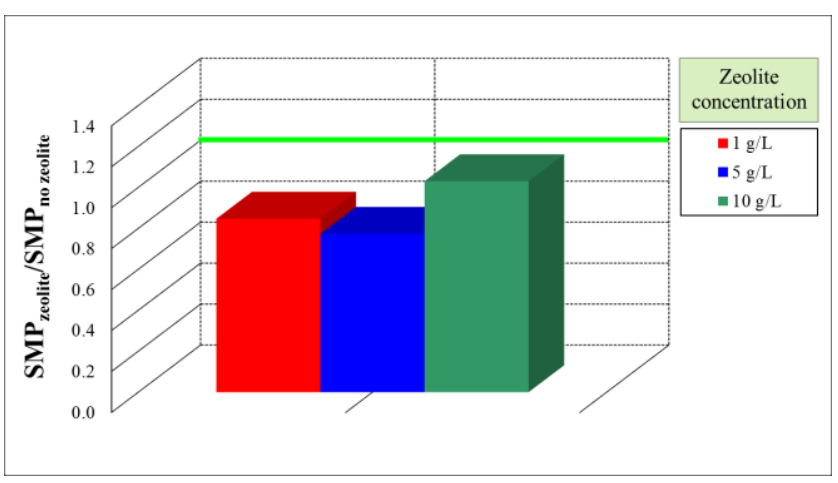

Figure 3. Effect of zeolite concentration (1, 5 and $10 \mathrm{~g} / \mathrm{L})$ on SMP removals

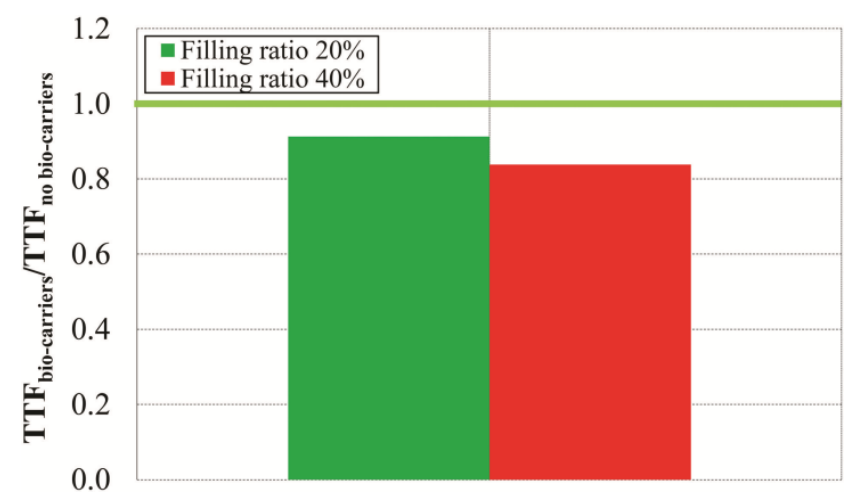

Figure 4. Effect of bio-carriers' filling ratio (20\% or $40 \%$ ) on sludge filterability

Considering bio-carriers, the ratios $\mathrm{TTF}_{\text {bio-carriers }} / \mathrm{TTF}_{\text {no bio- }}$ carriers and $\mathrm{SMP}_{\text {bio-carriers }} / \mathrm{SMP}_{\text {no bio-carriers }}$ are the ratios of $\mathrm{TTF}_{100}$ and SMP, respectively, after and before the addition of bio-carriers in the mixed liquor. It must be stated that if bio-carriers are dosed excessively, they may affect the membrane performance negatively: it is reported that collisions with the rigid bio-carriers may result in the deflocculation of large flocs to smaller ones which can foul membrane pores easier (Yoon, 2016; Wei et al., 2006). Thus, it was decided that their addition would take place at relatively low filling ratios, i.e. $20 \%$ and $40 \%$. As shown in Figure 4, the addition of bio-carriers at the filling ratio of $20 \%$ improved the reversible fouling by decreasing the measured times during the $\mathrm{TTF}_{100}$ method. Further increase of the filling ratio up to $40 \%$ resulted in even shorter measured values (times), confirming the beneficial effect of dosage increase on the reversible fouling. Regarding the irreversible fouling, both filling ratios (20\% and $40 \%)$ did not significantly reduce the SMP concentrations (Figure 5).

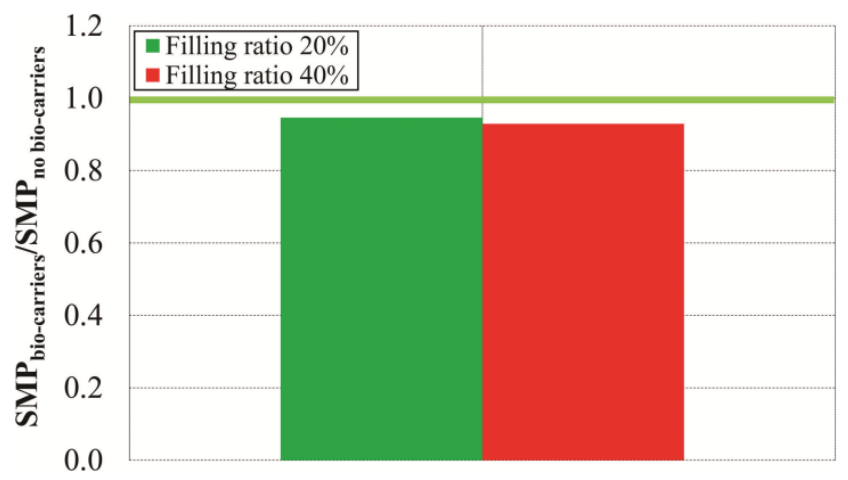

Figure 5. Effect of bio-carriers' filling ratio ( $20 \%$ or $40 \%)$ on SMP removals

Results suggest that the two additives could affect fouling alleviation complementary, since one additive (zeolite) mitigates mainly the irreversible fouling, while the other one (bio-carriers) mitigates the reversible fouling. Experiments which include their combined addition in the bioreactor at their optimal dosages are still in progress, however, preliminary measurements have shown some promising results (data not shown).
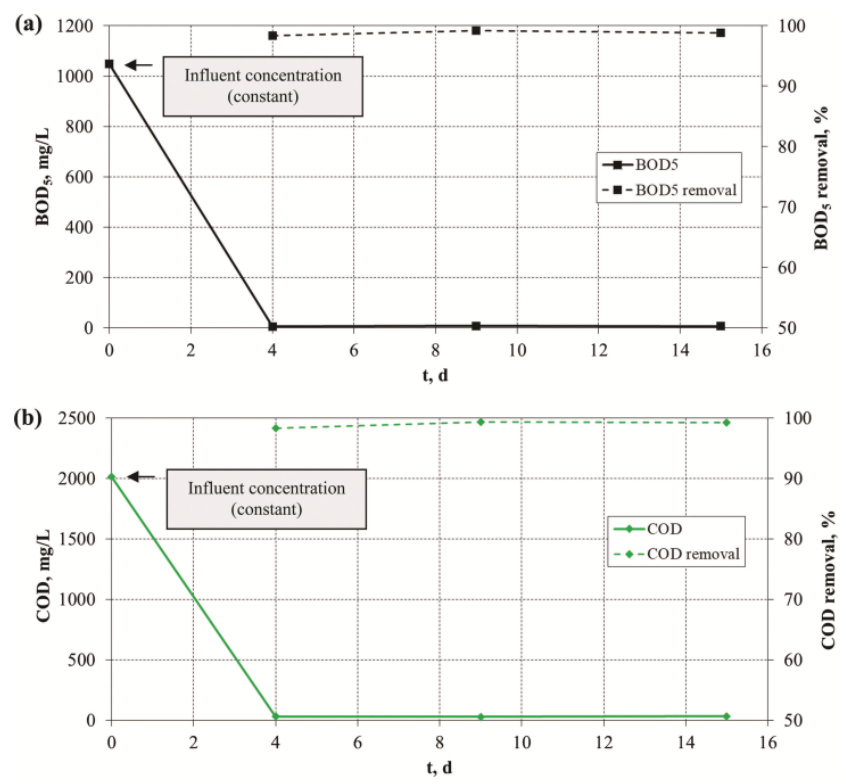

Figure 6. (a) $\mathrm{BOD}_{5}$ and (b) COD removal in the lab-scale MBR treatment system

\subsection{Lab-scale MBR performance}

Although the primary objective of the present study was the membrane fouling mitigation in MBR treatment systems by the addition of zeolite and bio-carriers, the system's performance was also assessed in terms of organics $\left(\mathrm{BOD}_{5}, \mathrm{COD}\right)$ and ammonium $\left(\mathrm{NH}_{4}^{+} \mathrm{N}\right)$ removal in order to estimate the environmental impact of the lab-scale MBR system, treating synthetic municipal 
wastewater of high strength. Results showed that $\mathrm{BOD}_{5}, \mathrm{COD}$ and $\mathrm{NH}_{4}^{+}-\mathrm{N}$ removals were more than $98 \%$ (Figures 6 and 7).

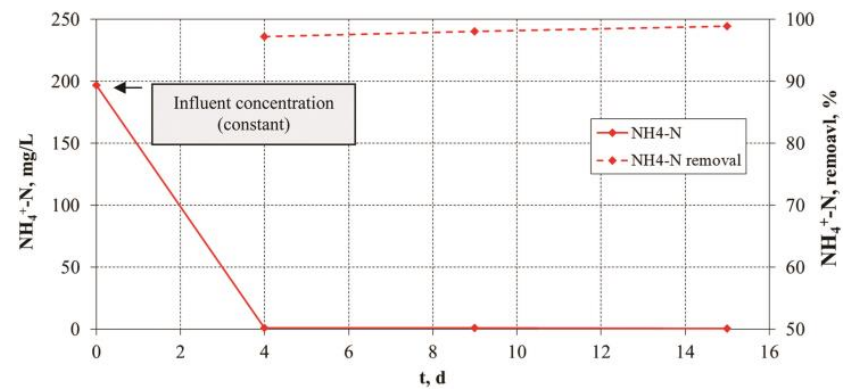

Figure 7. Ammonium removal in the lab-scale MBR treatment system

\section{Conclusions}

Membrane fouling still remains the most serious drawback in MBR treatment systems, leading gradually to membrane permeability decrease, efficiency deterioration and finally increased treatment cost, due to higher energy consumption, increase of TMP and the need for application of more frequent membrane cleaning procedures. In an effort to examine their effect on membrane fouling, various zeolite concentrations $(1,5$ and $10 \mathrm{~g} / \mathrm{L}$ ) and bio-carriers dosages ( $20 \%$ or $40 \%$ ) were added in the mixed liquor of a lab-scale MBR system, which treated high-strength synthetic municipal-type wastewater (batch experiments). Results showed that sludge filterability and, therefore, reversible fouling, was practically unaffected by the addition of zeolite at the high concentration examined $(10 \mathrm{~g} / \mathrm{L})$, while at the lower applied concentrations ( 1 and $5 \mathrm{~g} / \mathrm{L}$ ) it was slightly improved. Irreversible fouling was mitigated by the addition of zeolite at all concentrations; however, significant SMP removal was observed only at $5 \mathrm{~g} / \mathrm{L}$. Unlike zeolite, the addition of bio-carriers contributed mainly to the reversible fouling mitigation, especially at the filling ratio of $40 \%$. Regarding the system's treatment performance, the lab-scale MBR system operated successfully with a high-strength synthetic municipal wastewater, since it exhibited remarkable behaviour especially in terms of organics and ammonium removal (over 98\%).

\section{Acknowledgements}

This work has been financed by the State Scholarships Foundation (IKY), through the program "Research Projects for Excellence IKY/SIEMENS".

\section{References}

Akamatsu K., Lu W., Sugawara T. and Nakao S.-I. (2010), Development of a novel fouling suppression system in membrane bioreactors using an intermittent electric field, Water Research, 44, 825-830.

Boodhoo K. and Harvey A. (2013), Process Intensification for Green Chemistry: Engineering Solutions for Sustainable Chemical Processing, John Wiley \& Sons, Ltd., United Kingdom, Chapter 8, pp. 227-250.
Damayanti A., Ujang Z. and Salim M.R. (2011), The influenced of PAC, zeolite, and Moringa oleifera as biofouling reducer (BFR) on hybrid membrane bioreactor of palm oil mill effluent (POME), Bioresource Technology, 102, 4341-4346.

De la Torre T., Lesjean B., Drews A. and Kraume M. (2008), Monitoring of transparent exopolymer particles (TEP) in a membrane bioreactor (MBR) and correlation with other fouling indicators, Water Science and Technology, 58, 19031909.

Deng L., Guo W., Ngo H.H., Zhang H., Wang J., Li J., Xia S. and Wu Y. (2017) Biofouling and control approaches in membrane bioreactors, Bioresource Technology, 221, 656-665.

DuBois M., Gilles K., Hamilton J., Rebers P. and Smith F. (1956), Colorimetric method for determination of sugars and related substances, Analytical Chemistry, 28, 350-356.

Dutta K., Tsai C.-Y., Chen W.-H. and Lin J.-G. (2014), Effect of carriers on the performance of anaerobic sequencing batch biofilm reactor treating synthetic municipal wastewater, International Biodeterioration and Biodegradation, 95, 84-88.

Gkotsis P.K., Mitrakas M.M., Tolkou A.K. and Zouboulis A.I. (2017), Batch and continuous dosing of conventional and composite coagulation agents for fouling control in a pilot-scale MBR, Chemical Engineering Journal, 311, 255-264.

Iorhemen O.T., Hamza R.A. and Tay J.H. (2017), Membrane fouling control in membrane bioreactors (MBRs) using granular materials, Bioresource Technology, 240, 9-24.

Krzeminski P., Leverette L., Malamis S. and Katsou E. (2017), Membrane bioreactors - A review on recent developments in energy reduction, fouling control, novel configurations, LCE and market prospects, Journal of Membrane Science, 527, 207-227.

Lofrano G. (2012), Green Technologies for Wastewater Treatment; Energy Recovery and Emerging Compounds Removal, Springer, New York, Chapter 3, pp. 31-41.

Meng F., Chae S.-R., Drews A., Kraume M., Shin H.-S., Yang F. (2009) Recent advances in membrane bioreactors (MBRs): Membrane fouling and membrane material, Water Research, 43, 1489-1512.

Neoh C.H., Noor Z.Z., Mutamin N.S.A. and Lim C.K. (2016), Green technology in wastewater treatment technologies: Integration of membrane bioreactor with various wastewater treatment systems, Chemical Engineering Journal, 283, 582-594.

OECD (2010), OECD Guidelines for the Testing of Chemicals (Technical Report 209), Activated Sludge, Respiration Inhibition Test (Carbon and Ammonium Oxidation), Guideline 16.

Rezaei M. and Mehrnia M.R. (2014), The influence of zeolite (clinoptilolite) on the performance of a hybrid membrane bioreactor, Bioresource Technology, 158, 25-31.

Rosenberger S. and Kraume M. (2002), Filterability of activated sludge in membrane bioreactors, Desalination, 151, 195-200.

Wei C.-H., Huang X., Wang C.-W. and Wen X.-H. (2006), Effect of a suspended carrier on membrane fouling in a submerged membrane bioreactor, Water Science and Technology, 53(6), 211-220.

Wu Z., An Y., Wang Z., Yang S., Chen H., Zhou Z. and Mai S. (2008), Study on zeolite enhanced contact-adsorption regeneration-stabilization process for nitrogen removal, Journal of Hazardous Materials, 156, 317-326. 
Yoon S.-H (2016), Membrane Bioreactor Processes: Principles and Applications, CRC Press, New York, pp.228-230.

Yuniarto A., Noor Z.Z., Ujang Z., Olsson G., Aris A. and Hadibarata T. (2013), Bio-fouling reducers for improving the performance of an aerobic submerged membrane bioreactor treating palm oil mill effluent, Desalination, 316, 146-153. 